Comunicação: "Esboço de uma teoria das emoções": uma crítica e uma nova compreensão à psicologia das emoções, em Jean-Paul Sartre

\title{
"ESBOÇO DE UMA TEORIA DAS EMOÇÕES": UMA CRÍTICA E UMA NOVA COMPREENSÃO À PSICOLOGIA DAS EMOÇÕES, EM JEAN-PAUL SARTRE
}

\author{
"OUTLINE OF A THEORY OF EMOTIONS": A CRITIQUE AND A NEW UNDERSTANDING OF THE \\ PSYCHOLOGY OF EMOTIONS, IN JEAN-PAUL SARTRE
}

Thúlio Luis Ferreira*

\section{RESUMO}

Influenciado pela fenomenologia de Husserl, Sartre critica a filosofia idealista, bem como a Psicologia por seu caráter psicofisiológico e a Psicanálise com a noção de inconsciente. Para tanto, Sartre compreende o fenômeno da emoção como uma essência transcendental. A emoção, assim, é um modo de realização e transformação do mundo, um proceder de existir da consciência como forma organizada da existência humana em síntese.

PALAVRAS-CHAVE: Fenomenologia. Psicologia. Psicanálise. Sartre. Teoria das emoções.

\begin{abstract}
Influenced by the Husserl's phenomenology, Sartre critics the idealistic philosophy, as well as the Psychology by your character psychophysiological and the Psicanalysis and the notion of inconscient. Therefore, Sartre understands the phenomenon of the emotion like a transcedental essence. The emotion is a mode of realization and transformation of the world, a proceed of the conscience like organized form of the human existence in syntesis.
\end{abstract}

KEY-WORDS: Phenomenology. Psychology. Psicanalysis. Sartre. Theory of the emotions.

\section{INTRODUÇÃO}

Publicado em 1938, o Esboço para uma teoria das emoções executa uma crítica ao "mundo da interioridade" idealista, bem como a psicologia empírica, ao passo que oferece um novo quadro conceitual para compreender as emoções. Nesse itinerário, Sartre revisa as teorias contemporâneas da Psicologia até propor uma psicologia eidética. Nesse caso, o Esboço para uma teoria das emoções foi a única obra publicada de todo o seu trabalho de revisão da psicologia do século XX.

\footnotetext{
* Licenciado em Filosofia pelo Instituto Santo Tomás de Aquino. Pós-graduando em Filosofia Contemporânea no IEC, da PUC/Minas. Mestrando em Filosofia pela Faculdade Jesuíta de Filosofia e Teologia. E-mail: thuliosamonte@ hotmail.com.
} 


\section{CRÍTICA}

Enquanto para o idealismo a realidade está posta sob a égide de uma consciência que lhe confira validade, ou para o realismo, segundo o qual a consciência apreende a realidade a partir dos dados sensoriais, para Sartre a consciência é autônoma, tal como os objetos transcendentes.

A filosofia sartriana foi notadamente influenciada pela fenomenologia husserliana. Em Husserl a consciência intencional realiza um movimento permanente de transcendência em direção ao mundo, em que, diferente de Kant, o fenômeno coincide com o próprio ser do visado. Essa epistemologia identifica o ser dos fenômenos com o própria aparição apreendida pela consciência. Vazia de qualquer conteúdo e em transcendência na busca do "si”" que é o mundo concreto, a consciência é um Para-si, visa o que está fora dela mesma.

Com esse novo modus operandi, Sartre, na mesma perspectiva husserliana, procura exorcizar a psicologia da interioridade tão expressiva em seu tempo. Seu público situa-se entre psicólogos espiritualistas e filósofos idealistas: Lalande, Meyerson, Proust, Bergson, Brunschicg. Para eles a consciência é um receptáculo para o qual os objetos são atraídos e aí depositados. Endereçado à posição teórica desses mencionados Sartre escreve:

\footnotetext{
Ele comia com os olhos. Esta frase e muitos outros signos marcam suficientemente a ilusão comum ao realismo, segundo a qual conhecer é comer. A filosofia francesa, após cem anos de academicismo, ainda permanece nisso. [...] todos acreditamos que o Espírito-Aranha atraia as coisas para sua teia, cobri-as com uma baba branca e lentamente as deglutia, reduzindo-as à sua própria substância. O que é uma mesa, um rochedo, uma casa? Um certo composto de 'conteúdos da consciência', uma ordem desses conteúdos. (SARTRE, 2005, p. 87).
}

Sartre, em uma antífona da intencionalidade, diz: "toda consciência é consciência de", expulsa qualquer conteúdo na consciência, agora entendida como vazia, translúcida e absoluta, "ela não é nada senão o fora dela mesma e é esta fuga absoluta, esta recusa de ser substância que a constitui como uma consciência" (SARTRE, 2005, p. 88). A árvore, a casa, o rochedo, habitantes do interior de uma consciência na perspectiva da "filosofia alimentar", são situados fora da consciência, objetos transcendentes intencionados pela própria consciência. Com isso se efetua outra máxima da fenomenologia: "voltar às próprias coisas", isto é, restitui-se a objetividade do mundo. 
Comunicação: "Esboço de uma teoria das emoções": uma crítica e uma nova compreensão à psicologia das emoções, em Jean-Paul Sartre

mediterrânea. Ela não poderia entrar em vossa consciência, pois ela não tem a mesma natureza que a consciência. (SARTRE, 2005, p. 87).

O Esboço para uma teoria das emoções efetua uma crítica ao "mundo da interioridade" idealista, a partir do referencial da Psicologia. O projeto de Sartre era revisar toda a psicologia e propor uma nova teoria, não uma psicologia, mas subsídios à Psicologia.

A Psicologia do século XX, ambientada no positivismo, parte da repetição de fatos empíricos. Isso resulta em dois problemas. Primeiro, há uma indisplicência conceitual. A psicologia, diz Sartre, "não espera definir e limitar a priori o objeto de sua investigação. A noção de homem que ela aceita é inteiramente empírica: há no mundo um certo número de criaturas que oferecem à experiência caracteres análogos " (SARTRE, 2014, p. 14). Além disso, ao partir de fatos dispersos e sem definição do a priori, a Psicologia dispensa-se na multiplicidade de fatos isolados dando primazia ao acidente em detrimento do essencial. $\mathrm{O}$ psicólogo torna-se um colecionador de fatos dispersos contingentes.

\footnotetext{
Esperar o fato é, por definição, esperar o isolado, é preferir, por positivismo, o acidente ao essencial, o contingente ao necessário, a desordem à ordem; é transferir ao futuro, por principio, o essencial: 'é para mais tarde, quanto tivermos reunido um grande número de fatos'. (SARTRE, 2014, p. 16).
}

A argumentação de Sartre referenda as teorias de Janet e James, psicólogos preeminentes nos anos trinta. Em ambos, o estatuto da emoção é uma desordem orgânica, psico-fisológica.

Sartre (2014, p. 32) observa que para James "o estado de consciência dito 'alegria, cólera, etc.' é somente a consciência das manifestações fisiológicas, sua projeção na consciência”. A consciência não é mais que um reflexo das reações corporais. Assim, conferese primazia às reações do corpo em detrimento da consciência. Aqui, as emoções são a consciência de manifestações fisiológicas. O causalismo de James diria: estou triste porque choro ou alegre porque rio e não ao contrário, choro porque estou triste e rio porque estou alegre. Sua concepção de consciência é, pois, de ordem materialista.

Já em Janet as emoções são uma conduta e não apenas uma desordem orgânica. Contudo, embora ele considere as emoções no campo do psíquico e não do estritamente fisiológico, sua teoria assentada sobre as manifestações exteriores da emoção ainda conduzem aos fenômenos fisiológicos como acompanhantes aos fatos psicológicos. De modo que a consciência em Janet é 
ainda uma forma de behaviorismo, "um finalismo espontâneo e um mecanicismo de princípio (SARTRE, 2014, p. 40). Assim, a consciência é, como em James, secundária.

[...] ele julga que esses fenômenos são imediatamente suscetíveis de ser classificados em duas categorias: os fenômenos psíquicos ou condutas, os fenômenos psicológicos. Uma teoria da emoção que gostaria de restituir ao psíquico sua parte preponderante deveria fazer da emoção uma conduta. Mas Janet é sensível como James, apensar de tudo, à aparência de desordem que apresenta toda emoção. (SARTRE, 2014, p. 34).

No segundo capítulo do Esboço da teoria das emoções, Sartre promove uma discussão acerca da Psicanálise. Já é sabido que para ele é inconcebível uma consciência substancial. Também é intolerável uma consciência secundária, resultado causal de um lugar determinante que precede as próprias escolhas do homem. Ora, para a Psicanálise o desejo recalcado no inconsciente é anterior à vontade deliberada da pessoa. Assim sendo, Sartre rejeita o inconsciente freudiano, certo de que toda consciência é sempre consciência de e a partir de si mesma.

Entretanto, a Psicanálise serve a Sartre uma noção importante no raciocínio de sua teoria das emoções, a saber, o significado. Para a Psicanálise há analogia entre o conteúdo reprimido e o sintoma - expressão simbólica desse conteúdo. Sartre aprende com a teoria de Freud que "não se pode compreender a emoção se não lhe buscamos uma significação" (SARTRE, 2014, p. 47). Mas discorda que o significado da emoção esteja relacionado ao inconsciente. Para ele a consciência não é passiva de um conteúdo anterior, mas "é ela mesma o fato, a significação e o significado" (p. 51). De todo, a emoção tem um sentido, um significado que só será revelado pelo ato de tomada de consciência.

\footnotetext{
A interpretação psicanalítica concebe o fenômeno consciente como a realização simbólica de um desejo recalcado pela censura. Notemos que para a consciência esse desejo não está implicado em sua realização simbólica. Na medida em que existe pela e na nossa consciência, ele é unicamente aquilo pelo qual se dá: emoção, desejo de sono, roubo, fobia de loureiros, etc. se isso fosse de outro modo e tivéssemos qualquer consciência, mesmo explícita, de nosso verdadeiro desejo, nós estaríamos de má-fé e o psicanalista não o entende assim. (SARTRE, 2014, p. 49-50).
}

Vejamos agora a proposta de Sartre, uma psicologia fenomenológica.

\section{PSICOLOGIA FENOMENOLÓGICA: UMA NOVA TEORIA}

Ora, nosso trabalho até agora pretendeu apresentar os elementos com que Sartre constata a carência epistêmica da Psicologia. O psicólogo não pretende conhecer a totalidade 
Comunicação: "Esboço de uma teoria das emoções": uma crítica e uma nova compreensão à psicologia das emoções, em Jean-Paul Sartre

sintética do homem e do mundo, nem tanto conhecer as "condições de possibilidade de uma emoção, isto é, quanto a perguntar se a estrutura mesma da realidade humana torna as emoções possíveis e como as torna possíveis" (SARTRE, 2014, p. 18). Já para o fenomenólogo, se se conhece o homem que é uma totalidade sintética pode-se conhecer a essência da conduta das emoções. Ainda assim, o primeiro define as emoções como fisiológicas, não psíquicas e inativas; o segundo parte do princípio de que a emoção é uma resposta humana a realidade do mundo não como desordem psicofisiológica, mas como uma forma organizada da existência humana em síntese. A insuficiência metodológica da Psicologia não oferece condições para compreender o homem e, por conseguinte, as emoções.

\begin{abstract}
A primeira crítica que Sartre endereça à psicologia positiva é sua ausência de sistematicidade. A psicologia positiva pretende se limitar à experiência na qual ela entende em sentido muito restrito: esta experiência se limita a ser a experiência dos fatos. O psicólogo cientista não se pergunta se existe, como afirma Husserl, uma intuição de essências: ele pretende partir somente dos fatos, que ele define como qualquer coisa que se deve 'encontrar no curso de uma investigação' e que 'se apresenta como um enriquecimento inesperado e uma novidade por ligação aos fatos anteriores'. Sumariamente, seu estudo deve ser totalmente empírico e a posteriori. (TOMÈS, 2012, p. 224, tradução nossa).
\end{abstract}

Contra tais insuficiências Sartre convoca a fenomenologia de Husserl em que a noção de eidos (essência) contrasta com o catálogo dos fatos empíricos dos psicólogos. Aliás, para o autor de o Esboço da teoria das emoções, não há crítica à Psicologia se ela pretende de fato acumular conhecimentos do pormenor. Mas, se o objeto é alcançar uma síntese antropológica, então ela se equivoca e se contradiz, já que o método deve ser a investigação eidética dos fenômenos e não dos fatos particulares.

Sartre pretende oferecer um caminho de decifração das emoções que a partir da intuição eidética alcance a significação das essências das totalidades sintéticas em direção, pois, às coisas mesmas enquanto eidos. Para nosso autor, só a partir das essências, o irredutível na consciência transcendental a que Husserl chamou de noema, é que se pode examinar os fatos empíricos. Logo vemos, como já apontado, o esforço de superação da "filosofia da vida interior" é um anseio pelo concreto já que o "em-si" coincide com o próprio fenômeno.

Haverá então, por exemplo, uma fenomenologia da emoção que, após ter 'colocado o mundo entre parênteses', estudará a emoção como fenômeno transcendental puro, e isto se dirigindo não a emoções particulares, mas buscando alcançar e elucidar a essência transcendental da emoção como tipo organizado de consciência. (SARTRE, 1995, p. 14). 
A fenomenologia, ao colocar o mundo entre parênteses ${ }^{1}$, dispensa os fatos particulares da emoção e dedica-se a estudá-la como um fenômeno transcendental de modo a elucidar "a essencial transcendental da emoção como tipo organizado de consciência" (SARTRE, 2014, 22). Destarte, a Psicologia deve ser precedida pela fenomenologia que se ocupa das essências.

Outrossim, se a crítica de Sartre foi a negligência da Psicologia para com a essência da emoção é preciso que ele estude tal essência. No terceiro capítulo do Esboço da teoria das emoções, o autor defende que as emoções são irrefletidas, se reportam ao primeiro nível da consciência: "a consciência emocional é primeiramente irrefletida e, nesse plano, ela só pode ser consciência dela mesma no modo não posicional" (SARTRE, 2014, p. 55).

De acordo com Sartre, a consciência tem níveis diferentes. Enquanto atividade a consciência é consciência de si não tética, não posicional. À medida que ela visa à consciência reflexiva ela se torna tética de si, consciência do objeto.

Dessa afirmação decorre outra de igual valor, por via do raciocino lógico. Se a emoção é consciência, ainda que não teticamente, e que por seu próprio estatuto de que se dá sempre em direção ao mundo, consciência de, a emoção é um fenômeno de uma consciência no mundo. Diz Sartre: "a consciência emocional é, em primeiro lugar, consciência do mundo. Não é necessário ter presente toda a teoria da consciência para compreender claramente este princípio" (SARTRE, 2014. P. 55-56). É claro, se a consciência é um nada há de haver um ser que não seja ela, o mundo. Daí a emoção se dar em relação ao mundo.

De fato, é evidente que o homem que tem medo, tem medo de alguma coisa. Mesmo se é uma daquelas angústias indefinidas que sentimos na escuridão, numa passagem sinistra e deserta etc., é ainda de certos aspectos da noite, do mundo, que temos medo. [...] Não é preciso refletir muito para compreender, ao contrário, que a emoção retorna a todo instante ao objeto e dele se alimenta. [...] Em uma palavra, o sujeito emocionado e objeto emocionante estão unidos numa síntese indissolúvel. A emoção é uma certa maneira de apreender o mundo. (SARTRE, 2014, p. 56).

A propósito, chamar a emoção de um fenômeno e não de um fato diz respeito àquilo que aparece como sendo o próprio absoluto do aparecer. Já vimos que na fenomenologia não se distingue o aparecer e o ser do aparecer. Ainda mais, refere-se a emoção como significativa. Como sabemos, na perspectiva da psicologia empírica do fato a emoção é um acontecimento entre outros, um acidente e, "ao contrário, para o fenomenólogo, todo fato

\footnotetext{
1 "Se quisermos fundar uma psicologia, teremos que remontar mais acima que psíquico, mais acima que a situação do homem no mundo, até a origem do homem, do mundo e do psíquico: a consciência transcendental e constitutiva que alcançamos pela 'redução fenomenológica' ou 'colocação do mundo entre parênteses"” (SARTRE, 2014, p. 21)
} 
Comunicação: "Esboço de uma teoria das emoções": uma crítica e uma nova compreensão à psicologia das emoções, em Jean-Paul Sartre

humano é por essência, significativo. Se lhe tirarmos a significação, lhe retiramos sua natureza de fato humano. A tarefa do fenomenólogo será, pois, estudar a significação da emoção" (SARTRE, 2014, p. 25).

Considerar a emoção como fenômeno significativo é considerar também a realidade essencial do homem, uma vez que a emoção é à sua maneira o todo da consciência, ou o todo da realidade-humana. Influenciado por Heidegger, Sartre está convencido de que homem e mundo formam uma unidade sintética, ou seja, está organizado de forma a representar uma totalidade. Com isso é possível afirmar que toda emoção é uma forma de apreender o mundo, uma interação com os objetos da realidade. Afinal, o homem é um ser-no-mundo e a emoção é um comportamento desse homem que, por assim dizer, também revela sua própria essência.

Não se trata de transformar o objeto visado no mundo como tal, mas de transformar a própria consciência pelo corpo, “é o corpo, que dirigido pela consciência, muda suas relações com o mundo para que o mundo mude suas qualidades" (SARTRE, 2014, p. 64). É a própria consciência que altera a si mesma e, por conseguinte, o mundo na qual está contextualizada.

Sartre oferece alguns exemplos. No exemplo do medo passivo, o sujeito desmaia como uma maneira de aniquilar um animal quem vem em sua direção. Outra atitude: a fuga diante do animal feroz que corresponde ao desmaio, uma maneira de negar o perigo que vem em sua direção. Nesse caso Sartre chama de medo ativo. Todavia, em ambos os casos, contra a explicação da emoção como desordem fisiológica, Sartre passa a entender a emoção como uma reação, um modo de agir da consciência, em situação diante do mundo. A emoção deixa de ser um fato psicológico para ser uma resposta ativa ou passiva a uma situação concreta como uma maneira de negação mágica dos objetos no mundo. Dito de outra forma, a essência da emoção é ser um fenômeno da consciência, por meio de uma conduta irrefletida, que transforma o mundo em mundo mágico na tentativa de suprimir aquele objeto de dificuldade extrema.

Vejamos outro exemplo oferecido por Sartre. Alguém almeja alcançar um cacho de uvas. A parreira está longe fora do alcance da mão. Então, abaixa as mãos e diz "estão muito verdes", desiste. Logo, se sente o amargor da uva atribuindo a ela aquilo que desejo que ela seja. O diagnóstico é o mesmo: contra as dificuldades do mundo a consciência se refugia na emoção. Ela aparece para superar a tensão gerada por uma situação de desconforto.

Agora podemos conceber o que é uma emoção. É uma transformação do mundo. Quando os caminhos traçados se tornam muito difíceis ou quando não vemos caminho algum, não podemos mais permanecer num mundo tão urgente e tão difícil. 
Todos os caminhos estão barrados, no entanto é preciso agir. Então tentemos mudar o mundo, isto é, vivê-lo como se as relações das coisas com suas potencialidades não estivessem reguladas por processos deterministas, mas pela magia. (SARTRE, 2014, p. 62).

Em suma, para Sartre a emoção é um modo de o homem ser no mundo, de se relacionar com as situações de tensões e transformá-lo ao transformar a si mesmo. A filosofia de Sartre é uma filosofia do homem da ação.

\section{CONSIDERAÇÕES FINAIS}

A composição da obra Esboço para uma teoria das emoções denuncia duas referências capitais no pensamento sartriano, a saber, Husserl e Heidegger.

Quanto à inscrição da fenomenologia de Husserl, Sartre diz: "Husserl me envolvera, eu via tudo através das perspectivas da sua filosofia que, aliás, me era mais acessível por sua aparência cartesiana. Eu era 'husserliano' e assim ficaria por muito tempo" (SARTRE, 2005, p. 417). Até por volta de 1938 Sartre se afirmava husserliano, no entanto, como a própria citação aponta, essa partidarização a Husserl se deu durante muito tempo, mas não todo o tempo, houve uma ruptura.

Tal divergência se concentra, sobretudo, na tese da Transcendência do Ego, em que diferente de Husserl o Eu não é um habitante da consciência que unifica as seções captadas pela intenção. Em Sartre a própria consciência é sintética: “o objeto é transcendente às consciências que o apreendem e é nele que ela encontra sua unidade" (SARTRE, 1994, p, 97) e o Eu é transcendental: "Ego não está nem formalmente e nem materialmente na consciência: ele está fora, no mundo; é um ser do mundo tal como o Ego de outrem” (SARTRE, 1994, p. 94). Esta é uma novidade em Sartre, o ego está no mundo. ${ }^{2}$

Frustrado com Husserl, concomitante a redação do Esboço da Teoria das Emoções, Sartre lia Ser e Tempo, "quando comecei a ler Heidegger, no mês de abril, eu já estava saturado de Husserl" (SARTRE, 2005, p. 418). A ontologia de Heidegger fornece a Sartre a ideia do homem enquanto totalidade sintética, além de sua identificação com o mundo, "ora, o homem é um ser do mesmo tipo que o mundo, é mesmo possível, como acredita Heidegger,

\footnotetext{
2 Aqui, encontramos a originalidade da abordagem fenomenológica sartriana que se coloca como uma teoria existencialista da consciência ou como uma fenomenologia da existência humana. O ego é transcendente, não transcendental, afirma Sartre. O cogito é fruto da reflexão, ele é um objeto para a consciência. O ego encontra-se engajado no mundo (SOUZA, 2000, p. 63).
} 
Comunicação: "Esboço de uma teoria das emoções": uma crítica e uma nova compreensão à psicologia das emoções, em Jean-Paul Sartre

que as noções de mundo e de 'realidade-humana' (Dasein) sejam inseparáveis" (SARTRE, 1994, p.13).

Por fim, a interlocução com esses autores sob o contexto da Psicologia de seu tempo faz do Esboço da Teoria das Emoções uma oposição teórica a filosofia alimentar e garante a espontaneidade da consciência e a transcendência do mundo. Sartre à altura das exigências do seu tempo é um intelectual engajado que responde as solicitações da filosofia contemporânea.

\section{REFERÊNCIAS}

FUJIWARA, Gustavo. Fenomenologia e psicologia fenomenológica em Sartre: uma arqueologia dos conceitos. 2013. 252 f. Dissertação [Mestrado em Filosofia] - Escola de Filosofia, Letras e Ciências Humanas, Universidade Federal de São Paulo (UNIFESP), Guarulhos, 2013.

SARTRE, Jean-Paul. A transcendência do ego: esboço de uma descrição fenomenológica. Tradução e prefácio de Pedro M.S. Alves. Lisboa: Edições Colibri, 1994.

SARTRE, Jean-Paul. Esboço para uma teoria das emoções. Tradução de Paulo Neves. Porto Alegre: L\&PM, 2014.

SARTRE, Jean-Paul. Uma ideia fundamental da fenomenologia de Hussel: a intencionalidade. In: Situações I. São Paulo: Cosacnaify, 2005.

SASS, Simeão Donizeti. Esboço de uma teoria sartreana das emoções. Revista Reflexão, Campinas, v. 32, n. 92, p. 35-49, 2007.

SOUZA, José Carlos Aguiar de. Sartre e A transcendência do ego: uma abordagem nãoegológica da unidade e individualidade da consciência. Revista Psique, ano 10, n. 17, Nov. 2000 .

THOMÈS, Arnaud. Sartre et la critique des fondements de la psychologie: quelques piste sur les apports de Sartre et le Politzer. Bulletin d'analyse phénoménologique, v. 8, n. 1, p. 223 $244,2012$. 